\title{
KULEUVEN
}

\section{What do we want now or later? Work-family decisions in a dual-earner context}

Small Group Meeting EAWOP, 2021

Elisabeth Abraham \& Marijke Verbruggen

\section{Dual-earner couples}

- Dual-earner households as the norm today (Malconado \& Nieuwenhuis, 2015; OECD, 2011)

- Prone to work-family conflict (Greenhaus \& Beutell, 1985; Greenhaus et al., 1989; Masterson \& Hoobler, 2015; Radcliffe \& Cassel, 2014; Rapoport \& Rapoport, 1969)

$\Rightarrow$ uncertainty and complexity: align work-family preferences and commitments on an individual and a couple level, in the short and long run (Bailyn, 1977)

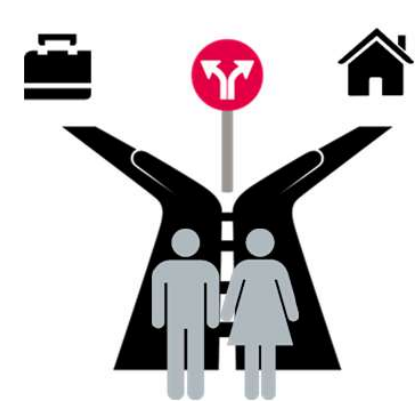

Impact on dual-earner work-family decisions 


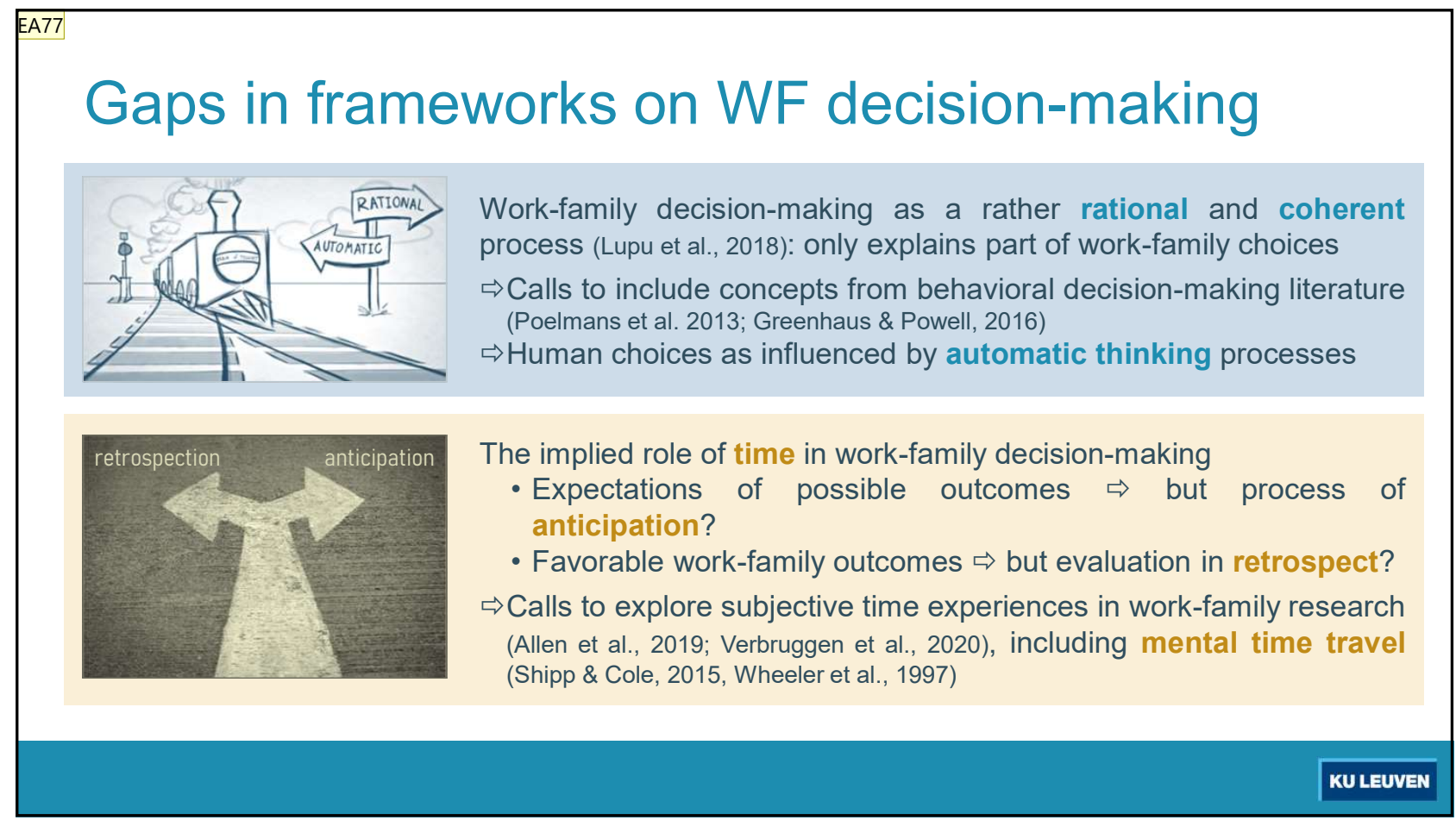

\section{Aims of our theoretical paper}

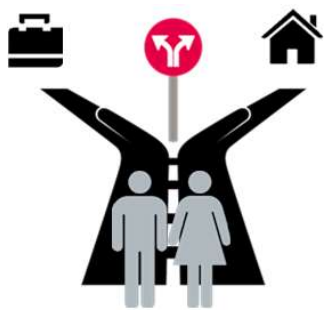

Extend frameworks on work-family conflict decisions in dualearner couples using a behavioral decision-making lens

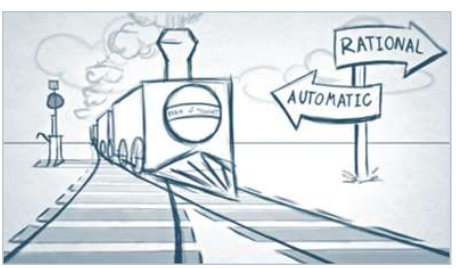

1. Argue that such decisions are particularly prone to irrational or incoherent influences like cognitive biases

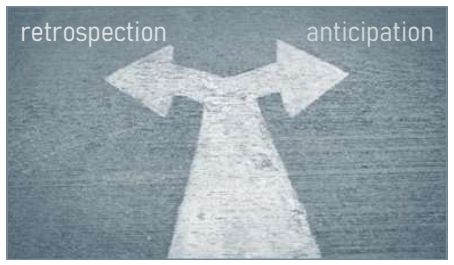

2. Investigate how cognitive biases impact time in workfamily decisions:

- the process of anticipation and retrospection

- daily and long term 
Slide 3

EA77 WF conflict \& couples nog eens herhalen?

Elisabeth Abraham; 9/04/2021 


\section{Daily decisions}

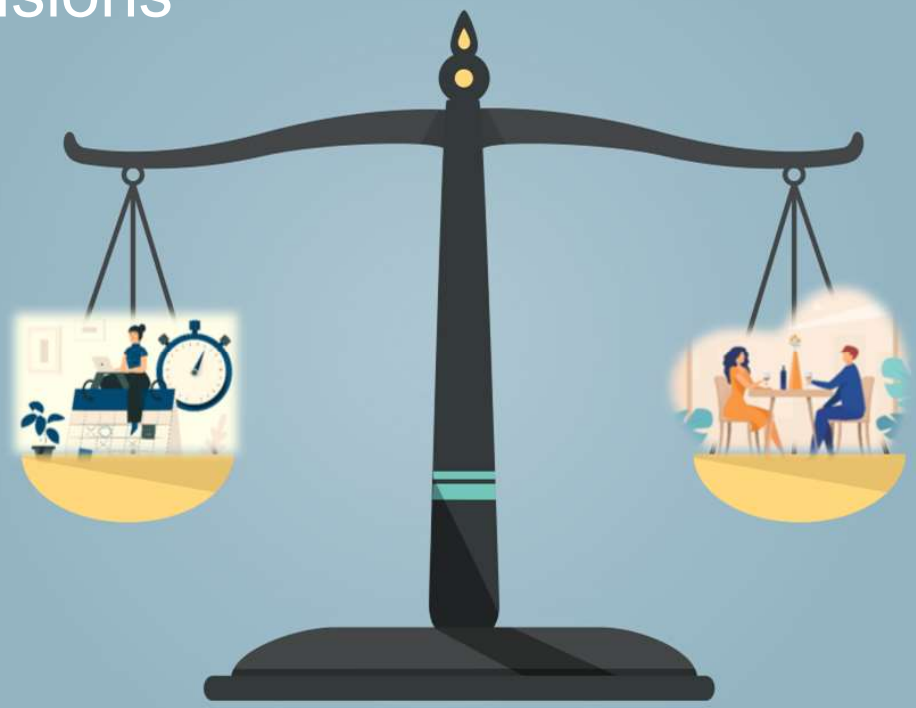

\section{Existing frameworks on daily WF decisions}

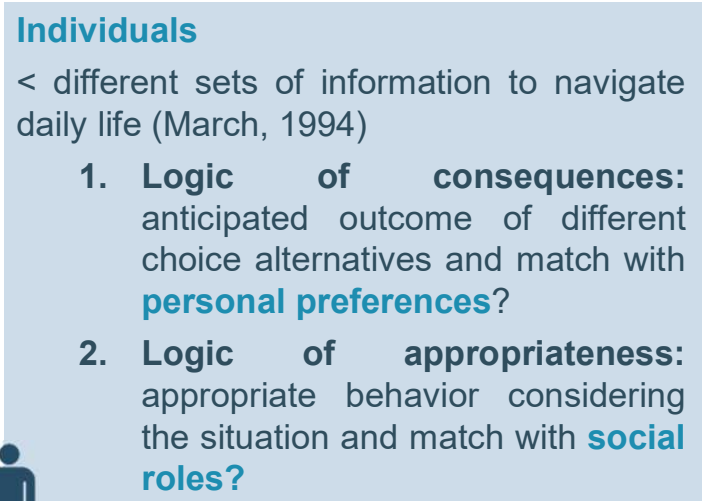

$<$ different sets of information to navigate daily life (March, 1994)

1. Logic of consequences: anticipated outcome of different choice alternatives and match with personal preferences?

2. Logic of appropriateness: appropriate behavior considering the situation and match with social roles?

\section{Couple rules to facilitate work-family} decisions

- Arise through explicit and prospective agreements or through silent and retrospective arrangement (Sillars \& Kalbflesch, 1989)

- Possible forms:

- Couple adaptive strategies (Becker \& Moen, 1999)

- Relational scripts (Crawford et al. 2019; Gioia \& Poole, 1984)

$\Rightarrow$ what (we think) we should do in a given conflict situation 


\section{Biased anticipations in the moment}

\section{Should \\ Before decision \\ Should \\ After decision}

Two mechanisms of the present bias (Bazerman et al., 1998; O'donoghue \& Rabin, 1999)

\section{Preporerate: act on momentary impulses}

$\Rightarrow$ in case of immediate gratification or when anticipating other decision options/outcomes is uncertain

2. Procrastinate: delay decision in the moment

$\Rightarrow$ in case of immediate costs or when anticipating/deciding is complex

\section{React on impulses in the moment \\ - not always in line with preferences, social roles or couple rules \\ - not always after careful} reflection about outcomes

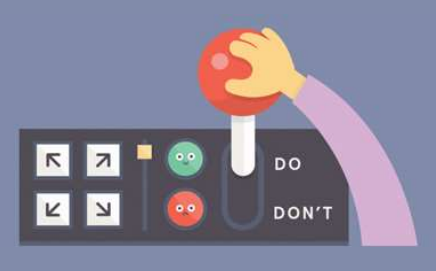

\section{Proposition 1a.}

The more daily work-family conflict decisions are characterized by uncertainty or complexity, the less likely partners in a couple decide rationally or coherently. 


\section{In retrospect}

Negative emotions like regret about unjustifiable decision outcome and process

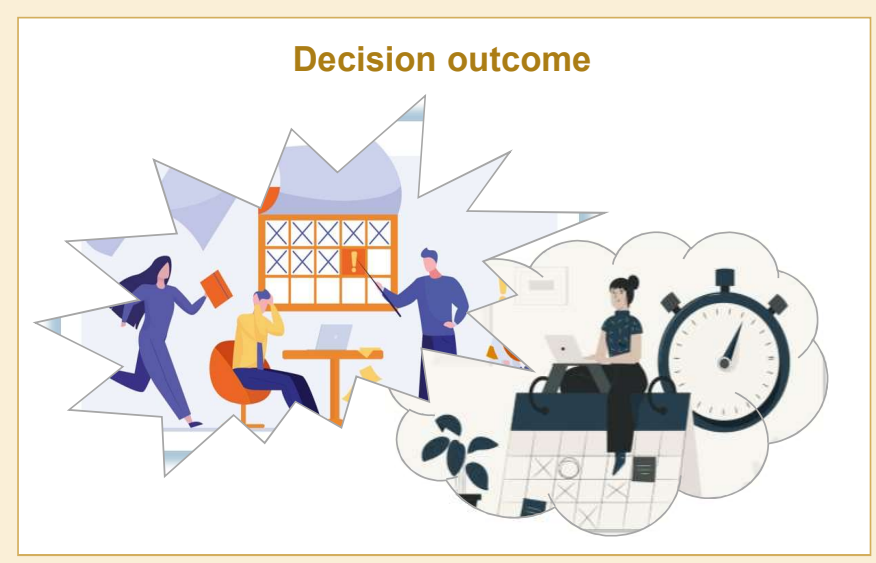

\section{Decision process}

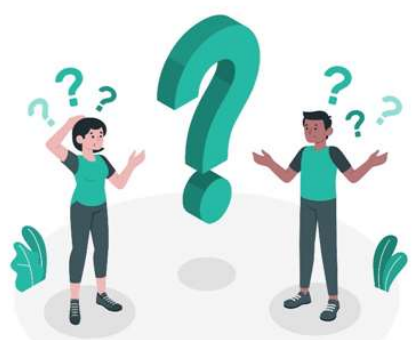

(Connolly \& Zeelenberg, 2002; Zeelenberg et al., 2002; Zeelenberg \& Pieters, 2010) KULEUVEN

\section{Proposition 16.}

The less daily work-family conflict decisions are made rationally or coherently, the more likely partners in a couple will experience negative retrospective emotions. 


\section{Existing frameworks on long-term WF decisions}

Individuals tend to take family into account when making work or career decisions (familyrelatedness of work decisions; Greenhaus \& Powell, 2012; Powell \& Greenhaus, 2012)

$\Rightarrow$ reach favorable outcome for the individual, but also for the family (Greenhaus \& Powell, 2016)
Couples navigate major career and family decisions together (Petriglieri, 2019; Radcliffe \& Cassell, 2014)

$\Rightarrow$ achieve a feasible combination

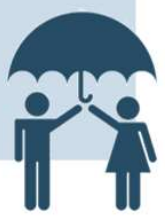

$\Rightarrow$ Which options are the best out of different alternatives? (Lupu et al., 2018) 


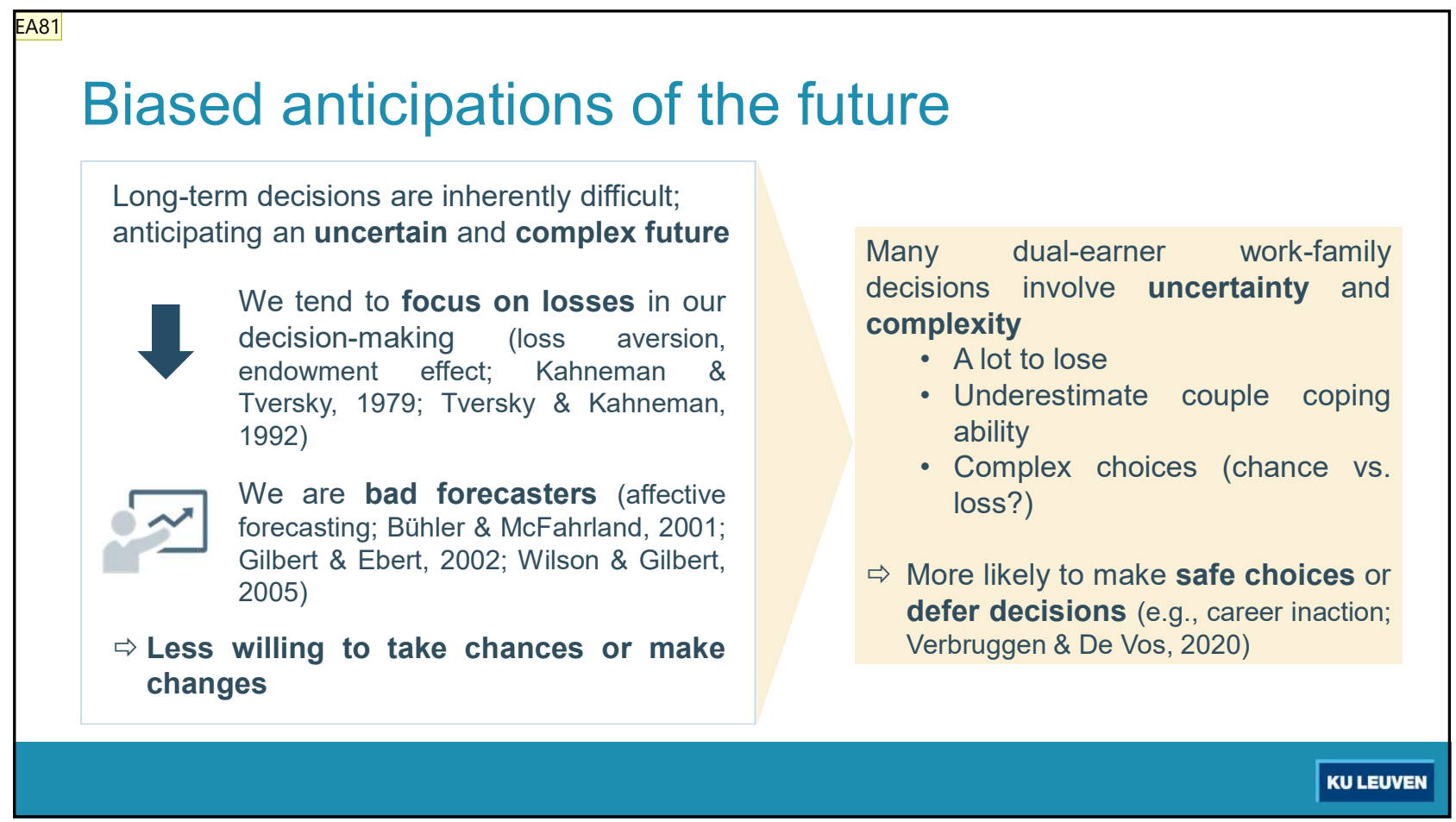

\section{Proposition 2a.}

The more long-term work-family decisions are characterized by uncertainty or complexity, the less likely partners in a couple will decide rationally or coherently. 
Slide 13

EA81 Integrate paper

Elisabeth Abraham; 9/04/2021 


\section{In retrospect}

\section{Cautious or deferred decisions $\Rightarrow$ negative experiences over time}

Regret about not acting

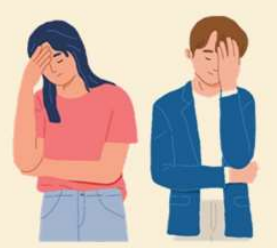

especially in important life domains like career, parenting, love (Roese \& Summerville, 2005)

\section{Unhappy with past decisions}

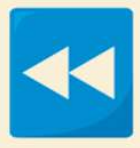

e.g., home-to-career interference

(Schooreel et al. 2017)

\section{Downward spiral for new} decisions

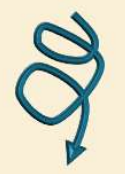

- Path dependency (Verbruggen et al., 2015)

- Inaction inertia (Tykocinski et al., 1995)

\section{Proposition $2 b$.}

The less long-term work-family conflict decisions are made rationally or coherently, the more likely partners in a couple will experience negative retrospective emotions. 


\section{Dealing with uncertainty and complexity}

Deal better with uncertainty and complexity when we can justify our choices, transfer decision responsibility or comprehend our preferences during decision-making and in retrospect (decision justification theory; Connolly \& Zeelenberg, 2002)

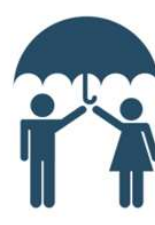

Couple context: possibility of justifying decisions together, sharing accountability and putting decisions into perspective

\section{Relational factors $\rightarrow$ dealing with} conflict

- Positivity in conflict (Gottman et al., 2015) $\Rightarrow$ reach consensus

- Secure-base relationships for career development (Petriglieri \& Obodaru, 2018) $\Rightarrow$ overcome fear of risk
$\Rightarrow$ Reduce impact of uncertainty and complexity

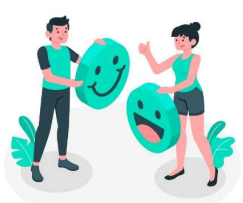

\section{Proposition 3.}

The more partners in a couple maintain positivity in couple interactions and a secure-base relationship, the less cognitive biases will impact their daily and long-term work-family decisions. EA101 
EA101 the less a) cognitive biases will impact ... b) less retrospective emotions ...

Elisabeth Abraham; 16/07/2021 


\section{Suggestions for further research}

Testing the framework

- Organize qualitative semi-structured interviews

- Study illogical decisions in quantitative designs (e.g., diary studies, longitudinal questionnaires)

intentions/commitments vs. decisions made

- Use small-sample designs (e.g., Hobbs et al. 2013)
Extending the framework

- Investigate aspects of the workfamily conflict situation (e.g., intensity, couple routines, ...)

- Examine role of emotions (aside from regret)

\section{Sources}

- $\underline{\text { Credits images }}$

- http://blog.thebreastcancersite.com/automatic-thoughts/ 
Slide 19

EA84 Update paper; versimpelen

Elisabeth Abraham; 9/04/2021 